\title{
A dose titration model for recombinant GH substitution aiming at normal plasma concentrations of IGF-I in hypopituitary adults
}

\author{
B Ekman ${ }^{1}$, T Lindström ${ }^{1}$, F Nyström ${ }^{1}$, A G Olsson ${ }^{1}$, G Toss ${ }^{1}$ and H J Arnqvist ${ }^{1,2}$ \\ ${ }^{1}$ Division of Internal Medicine, Department of Medicine and Care and ${ }^{2}$ Division of Cell Biology, Department of Biomedicine and Surgery, Faculty of Health \\ Sciences, Universitetssjukhuset, S-581 85 Linköping, Sweden \\ (Correspondence should be addressed to B Ekman; Email: Bertil.Ekman@lio.se)
}

\begin{abstract}
Objective: To evaluate a dose titration model for recombinant human GH substitution in adult patients with GH deficiency, aiming at normal plasma levels of IGF-I.

Design and methods: Eighteen patients participated and a start dose of $0.17 \mathrm{mg} \mathrm{GH} /$ day was used except by two men who started with $0.33 \mathrm{mg} /$ day. To demonstrate a clear GH effect the patients were first titrated, with steps of $0.17 \mathrm{mg} \mathrm{GH}$ /day every 6-8 weeks, to IGF-I levels in the upper range of age-adjusted reference values. The GH dose was then reduced 1 dose step and kept for a further 6 months. For comparison we investigated 17 healthy control subjects.

Results: Plasma IGF-I was increased after 2 weeks on the start dose and did not increase further for up to 8 weeks. Women had significantly lower GH sensitivity than men measured as net increment of IGF-I on the start dose of GH. GH sensitivity was not changed by age. The plasma IGF-I levels increased from $76.3 \pm 47.0$ (S.D.) to $237 \pm 97 \mu \mathrm{g} / \mathrm{l}$ at the end of the study $(P<0.001$ ), and similar IGF-I levels were obtained in both sexes. The maintenance median GH dose was $0.33 \mathrm{mg} /$ day in males and $0.83 \mathrm{mg} /$ day in females $(P=0.017)$. The $\mathrm{GH}$ dose correlated negatively with age in both sexes. Body weight, very low density triglycerides, lipoprotein(a) (Lp(a)), and fasting insulin increased, whereas insulin sensitivity index (QUICKI) decreased significantly. In comparison with the controls, the patients had lower fasting blood glucose, fasting insulin and Lp(a) levels at baseline, but these differences disappeared after GH substitution. The two groups had equal insulin sensitivity (QUICKI), but $2 \mathrm{~h}$ oral glucose tolerance test values of blood glucose and insulin were significantly higher in the patients at the end of the study.

Conclusions: In conclusion our data suggest that the starting dose of GH substitution and the dose titration steps should be individualised according to GH sensitivity (gender) and the IGF-I level aimed for (age). The reduced insulin sensitivity induced by GH substitution could be viewed as a normalisation if compared with control subjects.
\end{abstract}

European Journal of Endocrinology 147 49-57

\section{Introduction}

Retrospective studies have shown an increased mortality, mainly due to cardiovascular diseases, in patients with hypopituitarism not substituted with growth hormone (GH) (1). On the other hand GH excess in acromegaly is associated with diabetes mellitus, hypertension and premature death in malignant and cardiovascular disease $(2,3)$. Thus, both GH deficiency and excess of GH may be harmful. The GH-deficiency syndrome in adulthood is now well established and treatment with recombinant human $\mathrm{GH}$ has beneficial effects (4-6). These studies used high doses of $\mathrm{GH}$ without attention to gender and age and side-effects were common. The anabolic effects of $\mathrm{GH}$ on muscle, skeleton and other tissues in adult men are mediated by insulin-like growth factor-I (IGF-I) (7). Moreover, circulating IGF-I levels seem to be the best marker for evaluating the $\mathrm{GH}$ effect during $\mathrm{GH}$ treatment (8). Therefore, titrating the GH dose according to population-based reference values of IGF-I $(9,10)$ might be a way to obtain a fairly physiological substitution dose of GH. According to population-based reference materials there are no or little gender differences in IGF-I levels $(9,10)$. Few attempts of individualised dose titration of $\mathrm{GH}$ in $\mathrm{GH}$-deficient adults with close monitoring of IGF-I levels have been made. Johannsson et al. (11) dose titrated $\mathrm{GH}$ in GH-deficient adults according to both IGF-I levels and body composition, which resulted in many patients with supraphysiological 
IGF-I levels and lower IGF-I levels in women compared with men. Also Drake et al. (12) failed to obtain equal IGF-I levels in both genders after dose titration of GH using IGF-I as a marker of a $\mathrm{GH}$ effect.

Since excess of GH is harmful, we designed and evaluated a dose titration model for $\mathrm{GH}$ substitution for GH-deficient adults, aiming at normal levels of IGF-I according to previously established populationbased reference levels (9). We also investigated the effects of the titrated $\mathrm{GH}$ dose on anthropometric variables, lipids, carbohydrate metabolism and the frequency of adverse events.

\section{Subjects and methods}

\section{Patients}

We studied 18 adult hypopituitary subjects (11 men and 7 women, mean age 43 years; range 22-64), recruited from our outpatient care unit. Fourteen patients had adult onset and four patients had childhood onset (one male and three females) of GH deficiency. The mean duration from the diagnosis of $\mathrm{GH}$ deficiency was 17 years (range $1-44$ ). The patients had the following diagnoses: non-secreting pituitary adenoma (six), prolactinoma (five), idiopathic pituitary insufficiency (three), craniopharyngeoma (one), dysgerminoma (one), pituitary apoplexy (one) and pituitary stalk trauma (one). All patients, except one woman, had multiple hormone deficiencies and received additional hormonal replacement therapy if required: L-thyroxine $0.05-0.15 \mathrm{mg} /$ day (males/females,
$11 / 6$ ) and cortisone acetate $18.75-37.5 \mathrm{mg} /$ day (males/ females, nine/five); i.m. injection of testosterone enanthate every second to fourth week (ten males) and testosterone undecane orally (one male); ethinyl oestradiol/levonorgestrel orally (three females), oestradiol/norethisterone orally (two females) and vaginal oestrone therapy (one female); desmopressin orally (one female) and dopamine agonists (three males).

\section{Control subjects}

Reference values of IGF-I were calculated from 101 men and 101 women, 20-70 years of age, randomly selected from the population registry (9). The participation rate was $67 \%$ of those invited. The control group was selected from the above reference population and was matched as closely as possible, for height, weight, age and gender, to the GH-treated group. For the two shortest women we could not find control subjects within the matching criteria for height (i.e. the controls were taller), and therefore body mass index (BMI) was calculated to be sure that these control subjects did not differ markedly from the body proportions of the patients. Seventeen control subjects were enrolled and 16 subjects fulfilled the study (Table 1). The primary aim of using an untreated control group was to control during the course of the study for systematic errors in measurements and secondarily for comparison with the GH-deficient group on GH-dependent efficacy variables.

Table 1 Subjects characteristics (means \pm S.D. or median and range) at baseline $\left(T_{0}\right)$ and at the end of the study $\left(T_{\text {end }}\right)$.

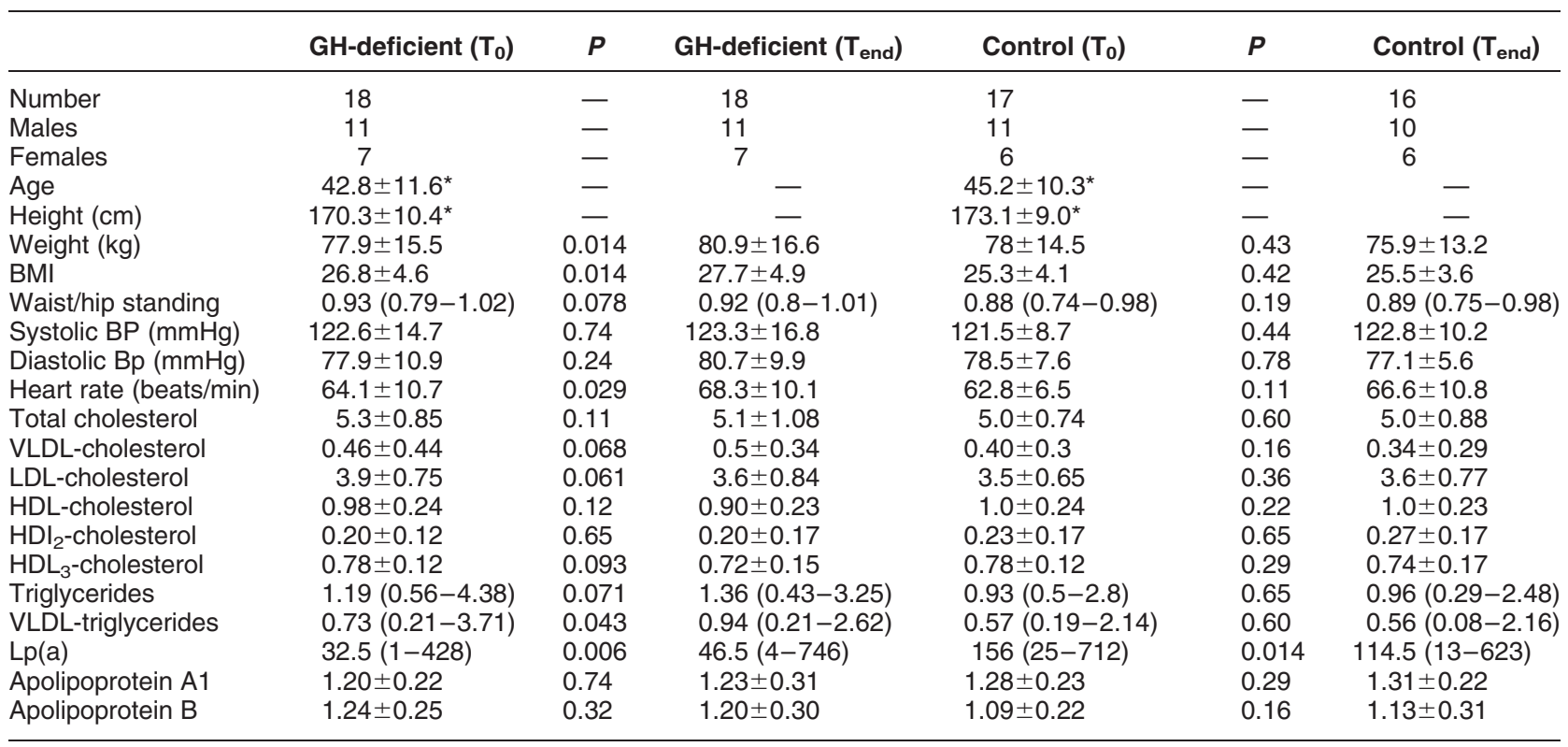

${ }^{*} P<0.05$ between groups. 


\section{Study design and treatment}

Patients were treated and assessed prospectively, and compared with an untreated healthy control group, using a defined protocol. The patients were on stable replacement therapy for other pituitary hormone deficiencies for at least 6 months before testing the $\mathrm{GH}$ reserve. Inclusion criteria for participation in the study were based upon maximal $\mathrm{GH}$ response to insulin-induced hypoglycaemia (blood glucose $<2.2 \mathrm{mmol} / \mathrm{l}$ ), and the mean $\mathrm{GH}$ peak value in the patients was $0.6 \mathrm{mU} / \mathrm{l}$ (range $0.05-2.4$ ). The patients were instructed on self-injection of GH (Norditropin; Novo Nordisk A/S, Denmark) using a pen-injection device (Nordiject 24; Novo Nordisk), and taught to inject the GH dose between 2000 and $2200 \mathrm{~h}$. The start dose of $\mathrm{GH}$ was defined according to body weight in the original protocol and the first two patients (two men) started with a daily dose of $0.33 \mathrm{mg} \mathrm{GH} /$ day (1.0 IU). However, due to symptomatic fluid retention the dose was reduced in these two patients to $0.17 \mathrm{mg} \mathrm{GH} /$ day after 2 weeks and 4 weeks respectively. Because of these adverse events an amendment was sent to the Swedish Medical Products Agency, and the start dose and the titration steps of $\mathrm{GH}$ were defined as a fixed dose of $0.17 \mathrm{mg}$ GH/day (0.5 IU) in the other 16 patients. The two male patients starting with $0.33 \mathrm{mg}$ followed the same protocol as the other 16 patients after the dose reduction (Fig. 1 shows the dose titration procedure in detail). The rationale for our dosing scheme was first to show a clear effect of the $\mathrm{GH}$ dose by titrating the dose until a high normal
IGF-I level was reached and then to slightly reduce the dose to achieve a maintenance $\mathrm{GH}$ dose giving IGF-I levels at or just below the mean.

\section{Ethics}

The study was approved by the local ethical committee and performed in accordance with the Declaration of Helsinki. Written informed consent was obtained from all patients and control subjects.

\section{Measurements}

Two specially trained research nurses did all anthropometric measurements and blood samplings. The same research nurse followed the individual patient and corresponding control subject during the study. Venous blood sampling was performed in the patients and the control subjects in the fasting state between 0730 and $0900 \mathrm{~h}$. IGF-I was measured at all visits and analysed within 2 weeks for dose adjustments. All other efficacy variables were evaluated at baseline $\left(\mathrm{T}_{0}\right)$ and at the end of the study $\left(\mathrm{T}_{\text {end }}\right)$.

\section{BMI and waist/hip ratio measurements}

BMI was calculated according to the formula weight (kg) divided by height $(\mathrm{m})$ squared. The circumference of the waist and hip was measured and the ratio was calculated. The measurement was made in duplicate and the mean of two values recorded.

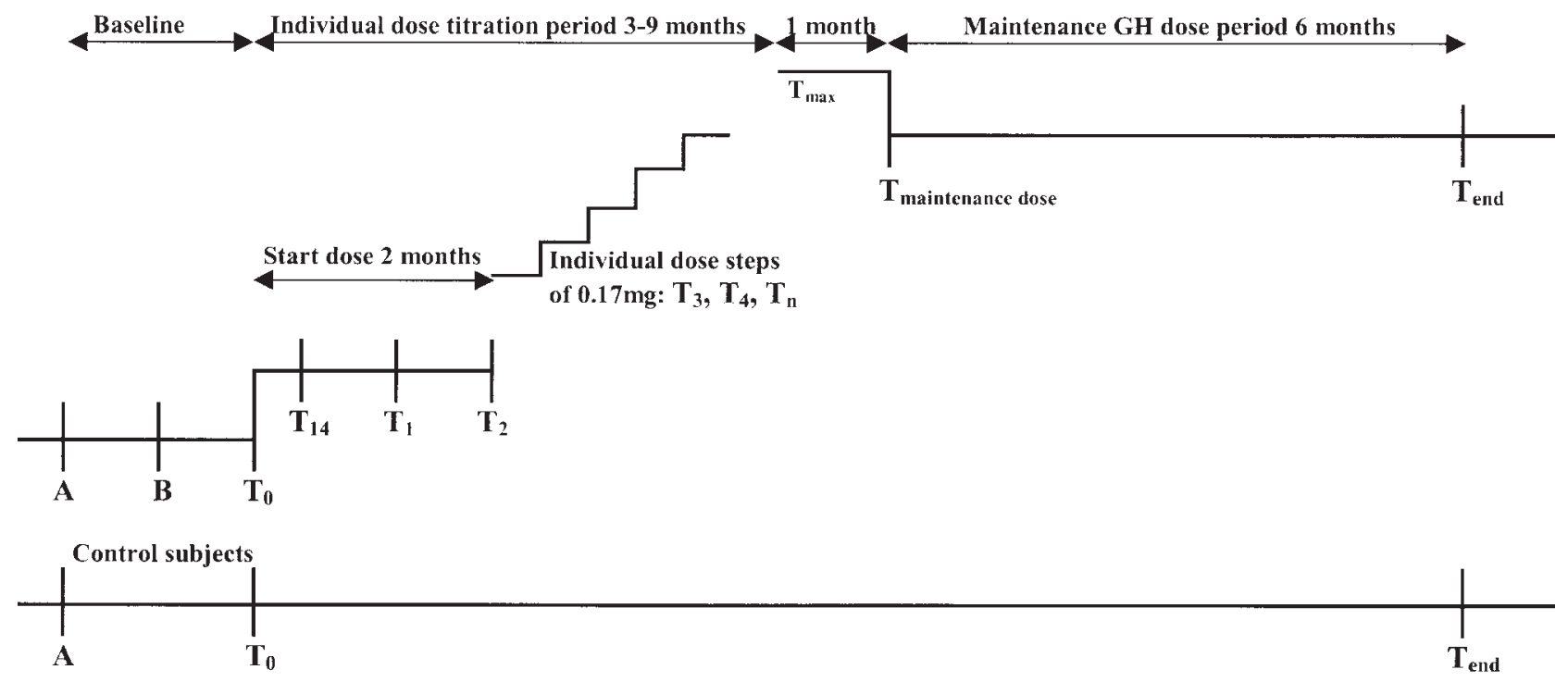

Figure 1 Dose titration procedure. $A=$ screening visit, $B=$ insulin-induced hypoglycaemia, $T_{0}=$ start of $G H$ substitution. The initial $G H$ dose was maintained for 2 months and IGF-I was measured after 14 days $\left(T_{14}\right), 1$ month $\left(T_{1}\right)$ and 2 months $\left(T_{2}\right)$. If the IGF-I value was below age-related mean +1 S.D. the GH dose was increased every 6-8 weeks in dose steps of $0.17 \mathrm{mg}\left(T_{3}, T_{4}, T_{n}\right)$. The GH dose giving IGF-I levels around the mean +1 S.D. $\left(T_{\max }\right)$ was maintained for another month and was then decreased by $0.17 \mathrm{mg}\left(\mathrm{T}_{\mathrm{maintenance}}\right.$ dose). The injection system (Nordiject) allowed steps of $0.17 \mathrm{mg} \mathrm{GH}$ and the lowest dose the patients could have was $0.17 \mathrm{mg} / \mathrm{day}$. The decreased $\mathrm{GH}$ dose was the maintenance dose and was held for a further 6 months to $\mathrm{T}_{\text {end. }}$. The untreated non-hypopituitary control subjects did the corresponding visits $A, T_{0}$ and $T_{\text {end }}$. 
Assessment of glucose tolerance (oral glucose tolerance test (OGTT)) and insulin sensitivity (QUICKI)

Glucose monohydrate $(75 \mathrm{~g})$ diluted in $500 \mathrm{ml}$ water was given orally and blood glucose and serum insulin concentrations were measured before and $2 \mathrm{~h}$ after glucose intake. Insulin sensitivity was calculated from fasting insulin $\left(\mathrm{I}_{0}\right)$ and blood glucose $\left(\mathrm{G}_{0}\right)$ levels using a quantitative insulin sensitivity check index (QUICKI = $1 /\left(\log \left(\mathrm{I}_{0}\right)+\log \left(\mathrm{G}_{0}\right)\right)(13)$. The units of blood glucose were converted from $\mathrm{mmol} / \mathrm{l}$ to $\mathrm{mg} / \mathrm{dl}$ and serum insulin from $\mathrm{pmol} / \mathrm{l}$ to $\mu \mathrm{U} / \mathrm{ml}$ in this index to give the possibility for comparisons (13).

\section{Assessment of plasma lipids and lipoproteins}

Blood was drawn in vacutainer tubes containing EDTA. The tubes were kept in iced water for about $1 \mathrm{~h}$ and then centrifuged at $2500 \mathrm{~g}$ for $10 \mathrm{~min}$ for separation of plasma and blood cells. Plasma was stored at $4^{\circ} \mathrm{C}$ no longer than $96 \mathrm{~h}$. Very low density (VLDL) lipoproteins were separated from low (LDL) and high density lipoproteins (HDL) by ultracentrifugation in a Centrikon T-2060 ultracentifuge (Kontron TFT 45.6, Switzerland) at $d=1.006 \mathrm{~kg} / \mathrm{l}$ as previously described (14). In the infranatant LDL was precipitated with phosphotungstic acid/magnesium chloride, leaving HDL in solution. Total and lipoprotein cholesterol and triglyceride concentrations were determined by enzymatic calorimetric methods (Monotest cholesterol CHOD-PAP and triglyceride GPO-PAP; Boehringer-Mannheim GmbH, Mannheim, Germany). LDL concentrations were obtained by the difference between concentrations in infranatant before and after precipitation. The $\mathrm{HDL}_{3}$ fraction was separated from the $\mathrm{HDL}_{2}$ fraction by ultracentrifugation of plasma at $d=$ $1.125 \mathrm{~kg} / \mathrm{l}$ as previously described. The infranatant $\mathrm{HDL}_{3}$ was removed for lipid analysis. The cholesterol concentration of $\mathrm{HDL}_{2}$ was calculated as the difference between $\mathrm{HDL}$ and $\mathrm{HDL}_{3}$ concentrations. Lipoprotein recoveries ((VLDL + LDL + HDL lipid $) /$ total lipid concentration $\times 100$ ) outside $90-110 \%$ for cholesterol and triglycerides were not accepted. Plasma total apolipoprotein A1 and B were determined by electroimmunoassay as previously described (15). Lipoprotein(a) (Lp(a)) was determined with an ELISA method (Biopool, Umeå, Sweden).

\section{Blood pressure and heart rate}

Blood pressure was measured in the supine position after 5 min rest. A mercury sphygmomanometer was used and the mean of two measurements in the right arm was recorded.

\section{Measurements on control subjects}

The control subjects did the same measurements as the patients at corresponding visits: a screening visit, at baseline $\left(\mathrm{T}_{0}\right)$ and at the end of the study $\left(\mathrm{T}_{\text {end }}\right)$.

\section{Assays}

Serum IGF-I was measured with a commercial kit (Nichols Institute, San Juan Capistrano, CA, USA) by RIA after acid-ethanol extraction of IGF-I from its binding proteins. The assay was performed according the manufacturer's protocol. Inter-assays coefficient of variation for serum IGF-I was $10 \%$. No difference between gender was found in our reference population regarding IGF-I levels (9) and predicted values of IGF-I were calculated from the entire population: $375-$ $(3.4 \times$ age $)$. The standard deviation score for IGF-I (IGF-I S.D. score) was then calculated: observed IGF-I value-predicted value/83.

GH was measured with a solid phase, two-site fluoroimmunometric assay (Wallac Oy, Turku, Finland). Serum insulin concentration was measured with an enzyme immunoassay from Dako Diagnostics Ltd, Cambs, UK. Capillary blood glucose was measured at the department of Clinical Chemistry with a glucose dehydrogenase method.

\section{Statistical analysis}

Statistical calculations were made using a personal computer and SPSS version 10 software. Baseline clinical characteristics are presented as means \pm S.D. or median and range. Differences within and between groups were tested with a paired two tailed $t$-test or a Wilcoxon signed rank sum test. Differences between gender were tested with an unpaired two tailed $t$-test or a Mann-Whitney U test. Multiple regression analysis was used to test possible explanatory variables affecting the maintenance $\mathrm{GH}$ dose. Differences of $P<0.05$ were considered significant.

\section{Results}

\section{Plasma IGF-I concentrations and titration of the GH dose}

Mean serum IGF-1 concentration before GH substitution was significantly lower in the GH-deficient group $(76.3 \pm 47.0 \mu \mathrm{g} / \mathrm{l})$ compared with the reference population (9) $(224 \pm 83 \mu \mathrm{g} / \mathrm{l}) \quad(P<0.001)$. Within the GH-deficient group there was a tendency to lower IGF-I levels in females at baseline (women 50土 $40 \mu \mathrm{g} / \mathrm{l}$ vs men $93 \pm 45 \mu \mathrm{g} / \mathrm{l}, P=0.052)$. Mean IGF-I concentration at the end of the study $\left(\mathrm{T}_{\text {end }}\right)$ on the maintenance dose of $\mathrm{GH}$ was $237 \pm 97 \mu \mathrm{g} / \mathrm{l}$ for the whole group $(P<0.001$ vs baseline $)$, and no difference was seen between genders (255 \pm 95 in males vs $209 \pm$ 
$102 \mu \mathrm{g} / \mathrm{l}$ in females, $P=0.34)$ ). The calculated mean IGF-I S.D. scores were at $\mathrm{T}_{\text {end }}$ : men $0.28 \pm 1$ and women $-0.20 \pm 1.2 \quad(P=0.38)$. Fourteen patients (seven men and seven women) who started with $0.17 \mathrm{mg}$ ( $0.5 \mathrm{IU})$ had evaluable IGF-I measurements after 2 weeks, 1 and 2 months. The IGF-I levels were significantly increased after 2 weeks $(P=0.021)$ on the lowest GH dose $(0.17 \mathrm{mg} /$ day $)$ and no further increase was found after 1 or 2 months on the same dose (Fig. 2). The net increment of plasma IGF-I on the start dose after 2 months, when all patients were treated with $0.17 \mathrm{mg} \mathrm{GH} /$ day, were $95 \pm 66 \mu \mathrm{g} / \mathrm{l}$ for men and $36 \pm 24 \mu \mathrm{g} / \mathrm{l}$ for women $(P<0.05)$ (Fig. 3). The mean increment of all the following dose steps did not differ significantly from the first step: men $58 \pm$ $24 \mu \mathrm{g} / \mathrm{l}$ and women $43 \pm 20 \mu \mathrm{g} / \mathrm{l}$. The individual IGF-I values in the GH-deficient group, in relation to population-based reference values before $\mathrm{GH}$ substitution $\left(\mathrm{T}_{0}\right)$, at the highest dose $\left(\mathrm{T}_{\max }\right)$ and at the end of the study on the maintenance dose $\left(\mathrm{T}_{\text {end }}\right)$ are shown in Fig. 4. To be noted was a very low IGF-I value in one female patient, probably caused by poor compliance, as her IGF-I value 3 months before the study end was well within our goals. In addition one man had an IGF-I level above 2 s.D. at the last visit and this could have been due to an analytical error during the titration period (i.e. inappropriately low IGF-I levels).

\section{Maintenance dose of GH}

The maintenance GH dose was the same as the next highest dose in the dose titration period. If the net number of dose steps (of $0.17 \mathrm{mg} /$ day) were calculated according to this dose, the median number of dose steps to reach the maintenance dose were 2 (range $1-7$ ) for the 11 males and 5 steps (range 2-8) for the seven females. The median GH dose was significantly affected by gender (males $0.33 \mathrm{mg} /$ day $(0.17-1.17)$ vs females $0.83 \mathrm{mg} /$ day $(0.33-1.33), P=0.017)$, and negatively correlated with age in both genders (Fig. 5). The three women with childhood onset of GH deficiency

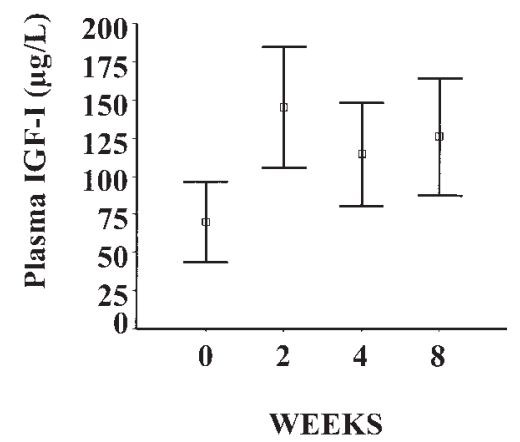

Figure 2 Mean IGF-I levels in 14 patients (seven males and seven females) at baseline and after 2, 4 and 8 weeks on the start dose of $0.17 \mathrm{mg} \mathrm{GH} /$ day. Data shown with $95 \%$ confidence intervals.

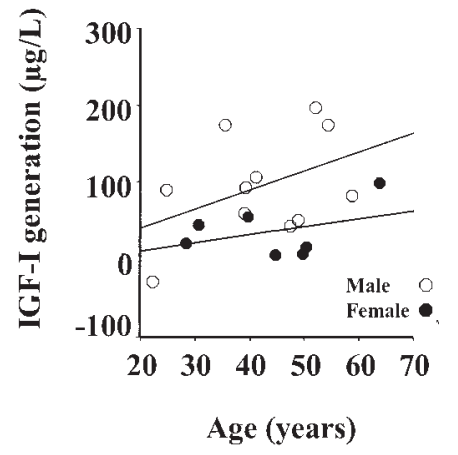

Figure 3 Net increment of circulating IGF-I after 2 months on the start dose in relation to age. All 18 patients had a GH dose of $0.17 \mathrm{mg} / \mathrm{day}$.

had a higher median maintenance $\mathrm{GH}$ dose, $1.0 \mathrm{mg}$ $(0.83-1.33)$, than the four women with adulthood onset, $0.6 \mathrm{mg}(0.33-1.0)(P=0.15)$. In a multivariate model with the maintenance $\mathrm{GH}$ dose as dependent
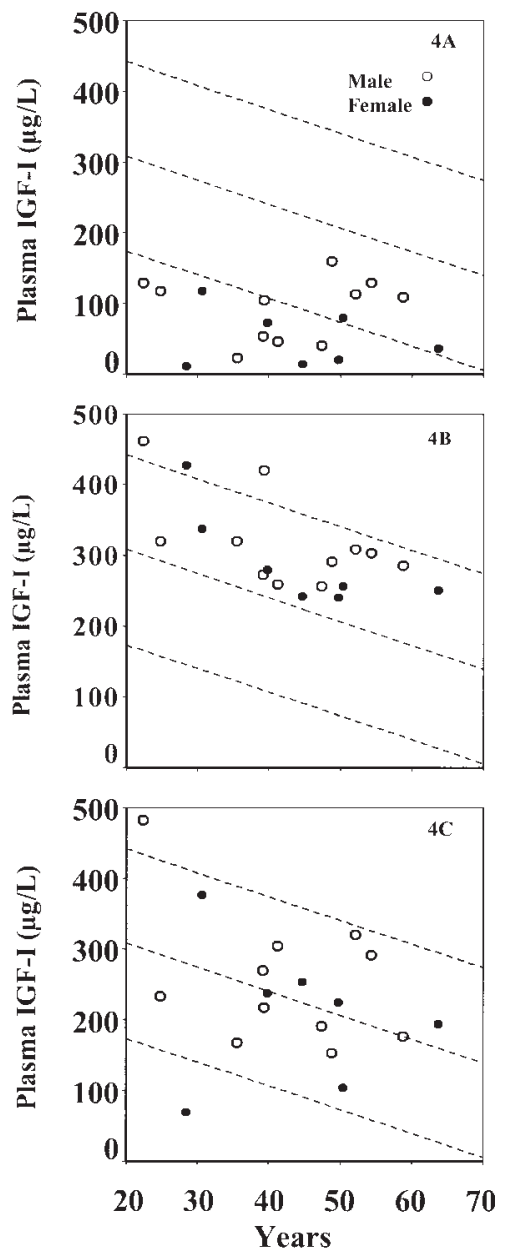

Figure 4 IGF-I levels in the GH-deficient group in comparison with age-adjusted reference values. (A) Before treatment $\left(T_{0}\right),(B)$ on the highest $\mathrm{GH}$ dose $\left(\mathrm{T}_{\max }\right),(\mathrm{C})$ after 6 months on the maintenance $\mathrm{GH}\left(\mathrm{T}_{\text {end }}\right)$. 


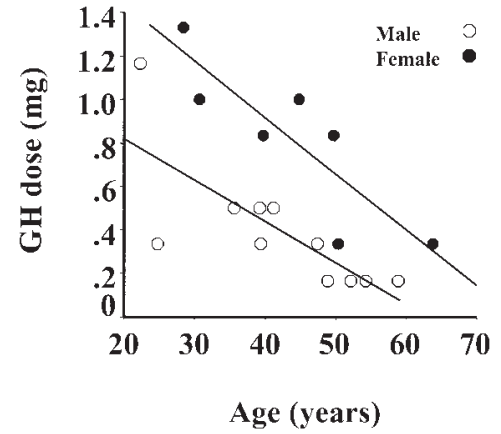

Figure 5 Maintenance doses of $\mathrm{GH}$ in women and men in relation to age.

factor, gender $(P=0.003)$, age $(P<0.001)$ and body weight $(P=0.004)$ were significant factors influencing the maintenance GH dose. Height or pre-treatment IGF-I levels did not predict the maintenance dose.

\section{Anthropometric characteristics and blood pressure}

Body weight, BMI and heart rate increased significantly in the GH-deficient group. Waist/hip ratio and systolic and diastolic blood pressure were unchanged during the study (Table 1).

\section{Blood glucose, serum insulin and insulin sensitivity}

All patients had blood glucose levels in the fasting state within the reference range at baseline. There was no significant change in fasting blood glucose levels $(4.1 \pm 0.4 \mathrm{mmol} / \mathrm{l}$ before substitution vs $4.3 \pm$ $0.4 \mathrm{mmol} / \mathrm{l}$ at the end of the study, $P=0.38$ ). Fasting insulin levels increased significantly during the study $(35.9 \pm 25.7 \mathrm{pmol} / \mathrm{l}$ vs $52.5 \pm 25.6 \mathrm{pmol} / \mathrm{l}, P=0.02)$. Prior to GH substitution one man and one woman had impaired glucose tolerance according to an OGTT, which in the man normalised during the study. No patient developed diabetes mellitus, but in addition two more patients developed impaired glucose tolerance at the end of the study. There was a tendency to increased $2 \mathrm{~h}$ concentrations of blood glucose (6.0 \pm 1.3 vs $6.5 \pm 1.5 \mathrm{mmol} / \mathrm{l}, P=0.13)$, and in serum insulin $(228.6 \pm 53.9$ vs $440.9 \pm 103.9 \mathrm{pmol} / \mathrm{l}, P=0.054)$ during GH substitution. Insulin sensitivity index (QUICKI) decreased after substitution $(0.41 \pm 0.07$ vs $0.36 \pm 0.03, P<0.02)$.

\section{Lipids and lipoproteins}

VLDL-triglycerides and $\mathrm{Lp}(\mathrm{a})$ increased significantly $(P=0.043$ and $P=0.006)$. Both HDL-cholesterol and LDL-cholesterol tended to decrease but the changes did not reach statistical significance. No changes were seen in total cholesterol, apolipoprotein A1 and B or the ratio between apolipoprotein B and LDL-cholesterol (Table 1).

\section{Adverse events}

In total 64 events were reported in the patients and most were graded as transient and mild. The most frequently reported adverse events were: complaints about the musculoskeletal system (ten patients), increased weight (seven patients), oedema (four patients), increased blood pressure (three patients) and decreased libido (three patients). The two men who started with a daily dose of $0.33 \mathrm{mg}$ both experienced early oedema, which disappeared after dose reduction, and two female subjects experienced transient oedema after 6 and 9 months respectively; both subjects were at that time treated with $1.0 \mathrm{mg} /$ day. Three patients were hospitalised during GH treatment: a 64-year-old female for exacerbation of pains due to known osteoarthritis, and as a consequence a previously planned arthroplasty was done; a 47-year-old man due to viral infection and signs of adrenal insufficiency; and a 24-year-old male previously operated for a cystic craniopharyngeoma who was treated with stereotactic instillation of radioactive yttrium in a known cyst, which had increased in size.

\section{Comparisons between the GH-deficient group and the control group before GH substitution}

Table 1 shows demographic data. A significant difference in IGF-I levels at baseline was found (76.3 \pm $47.0 \mu \mathrm{g} / \mathrm{l}$ in the GH-deficient group and $181 \pm$ $49.2 \mu \mathrm{g} / \mathrm{l}$ in the control group, $P<0.001)$. There were slight significant differences in age and height: GH-deficient group $43 \pm 12$ years and $171 \pm 11 \mathrm{~cm}$ vs control group $45 \pm 10$ years and $173 \pm 9 \mathrm{~cm}(P=$ 0.034 and $P=0.020)$. Fasting blood glucose was significantly lower in the GH-deficient group before substitution compared with the control group $(4.1 \pm 0.4 \mathrm{vs}$ $4.5 \pm 0.51, P=0.021)$, but there was no difference in the $2 \mathrm{~h}$ OGTT blood glucose levels between the two groups $(6.0 \pm 1.3$ vs $5.8 \pm 0.9 \mathrm{mmol} / \mathrm{l}, P=0.94)$. Fasting insulin levels in the GH-deficient group before treatment tended to be lower compared with levels in the control group (32.8 \pm 22.7 vs $60.2 \pm 53.7 \mathrm{pmol} / \mathrm{l}, \mathrm{P}=$ 0.089). No difference was found in $2 \mathrm{~h}$ insulin levels $(256 \pm 229$ vs $99 \pm 118 \mathrm{pmol} / \mathrm{l}, P=0.329)$. No significant differences were found in baseline plasma levels of lipids (Table 1).

\section{Comparisons between the GH-deficient group and the control group after GH substitution}

Within the control group no significant changes occurred during the study in bodyweight, BMI, waist/ hip ratio, blood pressure, heart rate, blood glucose, serum insulin levels in the fasting state or after OGTT, 
or in insulin sensitivity (QUICKI). No changes in the lipid concentrations were seen besides a significant decrease in $\operatorname{Lp}(\mathrm{a})(P=0.014)$ (Table 1$)$. The difference in fasting blood glucose between the $\mathrm{GH}$-deficient group and the control group disappeared $(4.3 \pm 0.4$ vs $4.5 \pm$ $0.51 \mathrm{mmol} / \mathrm{l}, P=0.17)$. The $2 \mathrm{~h}$ value of blood glucose during OGTT increased in the patients compared with the controls $(6.5 \pm 1.5$ vs $5.7 \pm 1.2 \mathrm{mmol} / \mathrm{l}, P=0.028)$. The fasting insulin levels tended to increase in the $\mathrm{GH}$ group and were equal to the control group (52.4 \pm 26.2 vs $63.9 \pm 57.5 \mathrm{pmol} / \mathrm{l}, P=0.483$ ). The $2 \mathrm{~h}$ value of serum insulin during OGTT increased in the patients

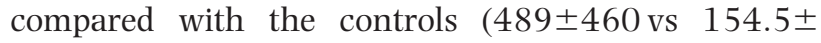
$94 \mathrm{pmol} / \mathrm{l}, P=0.018)$. No difference in insulin sensitivity (QUICKI) was found $(0.36 \pm 0.03$ in the patients and $0.36 \pm 0.04$ in the control subjects, $P=0.16)$.

\section{Discussion}

Since excess of $\mathrm{GH}$ is harmful we hypothesised that a GH dose giving circulating IGF-I levels at or slightly below the age-adjusted mean could be a safe and effective maintenance dose. To be sure of the GH effect and compliance, we first increased the dose stepwise to reach plasma levels of IGF-I well within the upper range of age-adjusted reference levels, whereafter the dose was reduced one step $(0.17 \mathrm{mg} /$ day $)$. With this titration procedure we could achieve, in both males and females, a clear effect of GH substitution, with circulating IGF-I levels close to the goal of treatment.

Even on the start dose of $0.17 \mathrm{mg} /$ day some male patients reached IGF-I levels in the upper range directly. In contrast, women tended to have lower IGF-I levels at baseline and significantly lower GH sensitivity measured as net increment of IGF-I on the start dose compared with the men (Fig. 3). In one dose titration study the patients started at $0.27 \mathrm{mg} \mathrm{GH} /$ day and a minority of the women but most of the men achieved age-adjusted IGF-I levels in the upper range directly on the start dose (12). Janssen et al. (16) studied doses of $0.2,0.4$ or $0.6 \mathrm{mg} \mathrm{GH} /$ day and found that a dose of $0.2 \mathrm{mg} /$ day was sufficient to normalise IGF-I levels in the majority of the male patients but not in the female patients. Available data thus strongly suggest that the start dose of GH should be individualised according to gender.

Already 2 weeks after the start of GH substitution the IGF-I levels were significantly increased, but the levels did not increase further after 1 or 2 months (Fig. 2). This is in accord with Drake et al. (12), who found increased IGF-I levels 2 weeks after the start of treatment and no additional increase after 4 weeks. This indicates that a full response of circulating IGF-I on the start dose can be measured within 2 weeks or even earlier. Even if dose adjustments could be done after 2 weeks according to IGF-I levels, it seems more physiological to use longer dose intervals, as the symptoms related to fluid retention seem to occur mainly during the first phase of GH treatment $(5,17)$. These early side-effects could be caused by increased $\mathrm{GH}$ sensitivity in the untreated state of $\mathrm{GH}$ deficiency (18). The intervals of $6-8$ weeks between dose adjustments of GH used in our study therefore seem reasonable to recommend.

Similar IGF-I levels were obtained in men and women but the median maintenance GH dose was significantly lower in males compared with females. Several studies have found gender differences in the IGF-I-generating effect of GH treatment $(19,20)$, but according to population-based reference materials there are no or little gender differences in IGF-I levels $(9,10)$. Analysis of $24 \mathrm{~h} \mathrm{GH}$ profiles showed a daily $\mathrm{GH}$ production $2-3$ times greater in women than in men to maintain an equivalent IGF-I level, suggesting that women need higher doses of GH (21). Even in dose titration studies with stepwise increments of the $\mathrm{GH}$ dose and despite a higher maintenance dose, females had lower IGF-I levels compared with males $(11,12,22)$. In contrast, our investigation showed that with systematic dose titration of $\mathrm{GH}$ an equal normalisation of IGF-I levels could be achieved in both males and females. However, our results could have been influenced by the fact that most women in the study used oral replacement of oestrogens, which could have decreased the IGF-I-generating effect of GH (23), and by the gender difference in the number of patients with childhood onset of $\mathrm{GH}$ deficiency (three females and one male) (24).

Like other investigators $(25,26)$, we found that some patients with GH deficiency had IGF-I levels within the lower part of the age-related reference range, and that this was more common in the elderly patients. Our dose titration model could be a solution to this problem. The $\mathrm{GH}$ dose is increased stepwise until a high normal ageadjusted IGF-I level (between 1 and 2 s.D.) has been achieved with a clear separation from baseline IGF-I levels, and the dose is then reduced to obtain IGF-I levels within defined goals. In analogy with the physiological decrease in $\mathrm{GH}$ secretion with increasing age (27) we found that the GH dose was lower in older age in both females and males in order to normalise the age-related IGF-I value (Fig. 5). This is in accord with the study by Toogood \& Shalet (26) who showed that elderly patients $(62-86$ years $)$ normalised their IGF-I levels or achieved levels above 2 s.D. for actual age with $\mathrm{GH}$ doses between 0.17 and $0.33 \mathrm{mg} /$ day. Since we found that the GH sensitivity did not change significantly with increasing age (Fig. 3), the lower $\mathrm{GH}$ dose in the elderly patients was to a great extent explained by the fact that age-adjusted IGF-I levels decrease with age $(9,10)$. Taking the data together we found that the size of the starting dose and the maintenance dose of $\mathrm{GH}$ should be individualised according to gender (GH sensitivity) and age (the magnitude of IGF-I increment aimed for). With newer injection systems now available and dependent of age and 
gender, starting GH doses of $0.1-0.2 \mathrm{mg} /$ day for young and middle-aged women and $0.05-0.1 \mathrm{mg} /$ day for men and old subjects of both genders seem appropriate. The size of the dose titration steps is then determined by the IGF-I-generating effect of this start dose and of the IGF-I levels aimed for. Moreover, the GH dose should be repeatedly revised in order to mimic the physiological fall in $\mathrm{GH}$ secretion rates and the correspondingly lower IGF-I levels by increasing age.

A key question was if the titrated $\mathrm{GH}$ dose giving physiological IGF-I levels had any effects on GH-dependent variables such as body composition, lipids and glucose tolerance previously described in studies using fixed high GH doses (4-6). With euglycaemic-hyperinsulinaemic clamp techniques increased insulin resistance in GH-deficient adults before $\mathrm{GH}$ treatment has been reported $(28,29)$. We used an index of insulin sensitivity (QUICKI) (13) to calculate insulin sensitivity in the fasting state and it was apparent that our GHdeficient patients were not insulin-resistant before substitution. After GH substitution there was an increase in insulin levels, a tendency towards higher fasting and $2 \mathrm{~h}$ glucose concentrations, and a significant decrease in insulin sensitivity index (QUICKI) indicating a decrease of insulin sensitivity. One possible explanation for this could be weight gain of the patients compared with the controls. The waist/hip ratio, however, remained unchanged indicating that the body composition had not changed unfavourably. Other studies using fixed high GH doses, with large proportions of the patients having supraphysiological IGF-I levels, have shown beneficial effects on body composition with increased lean body mass and decreased fat mass but despite that an impaired glucose tolerance $(4,6)$. Even though our patients had IGF-I levels well within the reference range for age, GH substitution did reduce insulin sensitivity. In agreement with our data, Rosenfalck et al. (30) also found a decrease in glucose tolerance in several patients despite IGF-I levels in the normal range during $\mathrm{GH}$ treatment. In contrast Bulow \& Erfurth (31) found no change in glucose tolerance in young adults treated with GH. In our study the decreased insulin sensitivity caused by GH could be viewed as a normalisation in most patients if compared with the control subjects, but the physiological range seems narrow as two patients developed impaired glucose tolerance during the study.

We found no obvious dyslipidaemia at baseline in the GH-deficient group in contrast to other studies (32-34) or when compared with the control group. The controls were in general 2 years older, which could have masked a difference between the two groups, but according to the natural course of cholesterol concentrations during life it seems that the age difference was of minor importance (35). Our patients had normal waist/hip ratios and glucose tolerance, which in part could explain the differences from previous studies, as $\mathrm{GH}$ deficiency has been associated with central adiposity
(36) and insulin resistance (29). Although most of the changes in the lipoprotein concentrations during GH substitution did not reach statistical significance the changes taken together support the concept of decreased insulin sensitivity. Increase of plasma triglycerides or VLDL-triglyceride concentration and lowering of plasma HDL-cholesterol concentration are commonly found in insulin-resistant individuals with obesity or type 2 diabetes (37). As observed in several studies, Lp(a) increased during GH substitution (38, 39) but no difference between the GH-deficient group and the control group could be found at the end of the study, questioning the clinical importance.

In conclusion our data suggest that the starting dose of GH substitution and the dose titration steps should be individualised according to GH sensitivity (gender) and the IGF-I level aimed for (age). Even if the reduced insulin sensitivity by GH substitution could be viewed as a normalisation if compared with control subjects, it seems appropriate to monitor glucose tolerance repeatedly with an OGTT.

\section{Acknowledgements}

We are grateful to Novo Nordisk A/S, Denmark, for their financial support of the study. Grants were also obtained from the Swedish Medical Research Council (04952 and 06962), and from the University of Linköping, Sweden. The authors wish to thank Christina Dahlgren, Kerstin Krogager, Ylva Lindegård, Britt Sigfridsson and Margareta Karlsson for skilful technical assistance.

\section{References}

1 Rosen T \& Bengtsson BA. Premature mortality due to cardiovascular disease in hypopituitarism. Lancet 1990336 285-288.

2 Orme SM, McNally RJ, Cartwright RA \& Belchetz PE. Mortality and cancer incidence in acromegaly: a retrospective cohort study. United Kingdom Acromegaly Study Group. Journal of Clinical Endocrinology and Metabolism 199883 2730-2734.

3 Colao A, Baldelli R, Marzullo P, Ferretti E, Ferone D, Gargiulo P et al. Systemic hypertension and impaired glucose tolerance are independently correlated to the severity of the acromegalic cardiomyopathy. Journal of Clinical Endocrinology and Metabolism 2000 85 193-199.

4 Salomon F, Cuneo RC, Hesp R \& Sonksen PH. The effects of treatment with recombinant human growth hormone on body composition and metabolism in adults with growth hormone deficiency. New England Journal of Medicine 1989321 1797-1803.

5 Jorgensen JO, Pedersen SA, Thuesen L, Jorgensen J, IngemannHansen T, Skakkebaek NE et al. Beneficial effects of growth hormone treatment in GH-deficient adults. Lancet 198911221 1225.

6 Cuneo RC, Judd S, Wallace JD, Perry-Keene D, Burger H, Lim-Tio S et al. The Australian multicenter trial of growth hormone (GH) treatment in GH-deficient adults. Journal of Clinical Endocrinology and Metabolism $1998 \mathbf{8 3} 107-116$.

7 Le Roith D. Seminars in medicine of the Beth Israel Deaconess Medical Center. Insulin-like growth factors. New England Journal of Medicine 1997336 633-640.

8 de Boer H, Blok GJ, Popp-Snijders C, Stuurman L, Baxter RC \& van der Veen E. Monitoring of growth hormone replacement therapy 
in adults, based on measurement of serum markers. Journal of Clinical Endocrinology and Metabolism 199681 1371-1377.

9 Nystrom FH, Ohman PK, Ekman BA, Osterlund MK, Karlberg BE \& Arnqvist HJ. Population-based reference values for IGF-I and IGF-binding protein-1: relations with metabolic and anthropometric variables. European Journal of Endocrinology 1997136 165-172.

10 Hilding A, Hall K, Wivall-Helleryd IL, Saaf M, Melin AL \& Thoren M. Serum levels of insulin-like growth factor I in 152 patients with growth hormone deficiency, aged 19-82 years, in relation to those in healthy subjects. Journal of Clinical Endocrinology and Metabolism 199984 2013-2019.

11 Johannsson G, Rosen T \& Bengtsson BA. Individualized dose titration of growth hormone $(\mathrm{GH})$ during $\mathrm{GH}$ replacement in hypopituitary adults. Clinical Endocrinology $1997 \mathbf{4 7} 571-581$.

12 Drake WM, Coyte D, Camacho-Hubner C, Jivanji NM, Kaltsas G, Wood DF et al. Optimizing growth hormone replacement therapy by dose titration in hypopituitary adults. Journal of Clinical Endocrinology and Metabolism 199883 3913-3919.

13 Katz A, Nambi SS, Mather K, Baron AD, Follmann DA, Sullivan G et al. Quantitative insulin sensitivity check index: a simple, accurate method for assessing insulin sensitivity in humans. Journal of Clinical Endocrinology and Metabolism $2000852402-2410$.

14 Wallentin L, Fahraeus L. $\mathrm{HDL}_{3}$ and $\mathrm{HDL}_{2}$ determination by a combined ultracentrifugation and precipitation procedure. Clinica Chimica Acta $1981 \mathbf{1 1 6} 199-208$.

15 Molgaard J, von Schenck H \& Olsson AG. Comparative effects of simvastatin and cholestyramine in treatment of patients with hypercholesterolaemia. European Journal of Clinical Pharmacology $198936455-460$.

16 Janssen YJ, Frolich M \& Roelfsema F. A low starting dose of genotropin in growth hormone-deficient adults. Journal of Clinical Endocrinology and Metabolism 199782 129-135.

17 Cuneo RC, Salomon F, McGauley GA \& Sonksen PH. The growth hormone deficiency syndrome in adults. Clinical Endocrinology $199237387-397$.

18 Aimaretti G, Fanciulli G, Bellone S, Maccario M, Arvat E, Delitala $\mathrm{G}$ et al. Enhancement of the peripheral sensitivity to growth hormone in adults with GH deficiency. European Journal of Endocrinology $2001145267-272$.

19 Burman P, Johansson AG, Siegbahn A, Vessby B \& Karlsson FA. Growth hormone $(\mathrm{GH})$-deficient men are more responsive to $\mathrm{GH}$ replacement therapy than women. Journal of Clinical Endocrinology and Metabolism 199782 550-555.

20 Johannsson G, Bjarnason R, Bramnert M, Carlsson LM, Degerblad $\mathrm{M}$, Manhem $\mathrm{P}$ et al. The individual responsiveness to growth hormone $(\mathrm{GH})$ treatment in $\mathrm{GH}$-deficient adults is dependent on the level of GH-binding protein, body mass index, age, and gender. Journal of Clinical Endocrinology and Metabolism $1996 \mathbf{8 1}$ $1575-1581$.

21 van den Berg G, Veldhuis JD, Frolich M \& Roelfsema F. An amplitude-specific divergence in the pulsatile mode of growth hormone (GH) secretion underlies the gender difference in mean GH concentrations in men and premenopausal women. Journal of Clinical Endocrinology and Metabolism 199681 2460-2467.

22 Murray RD, Skillicorn CJ, Howell SJ, Lissett CA, Rahim A \& Shalet SM. Dose titration and patient selection increases the efficacy of GH replacement in severely GH deficient adults. Clinical Endocrinology $199950749-757$.

23 Janssen YJ, Helmerhorst F, Frolich M \& Roelfsema F. A switch from oral ( $2 \mathrm{mg} /$ day) to transdermal ( $50 \mathrm{microg} /$ day) 17 beta-estradiol therapy increases serum insulin-like growth factor-I levels in recombinant human growth hormone $(\mathrm{GH})$-substituted women with GH deficiency. Journal of Clinical Endocrinology and Metabolism $200085464-467$.
24 Murray RD, Howell SJ, Lissett CA \& Shalet SM. Pre-treatment IGF-I level is the major determinant of GH dosage in adult GH deficiency. Clinical Endocrinology 200052 537-542.

25 Ho KY \& Weissberger AJ. Secretory patterns of growth hormone according to sex and age. Hormone Research 199033 7-11.

26 Toogood AA \& Shalet SM. Growth hormone replacement therapy in the elderly with hypothalamic-pituitary disease: a dose-finding study. Journal of Clinical Endocrinology and Metabolism $1999 \mathbf{8 4}$ 131-136.

27 Ho KY, Evans WS, Blizzard RM, Veldhuis JD, Merriam GR, Samojlik E et al. Effects of sex and age on the 24-hour profile of growth hormone secretion in man: importance of endogenous estradiol concentrations. Journal of Clinical Endocrinology and Metabolism $19876451-58$.

28 Johansson JO, Fowelin J, Landin K, Lager I \& Bengtsson BA. Growth hormone-deficient adults are insulin-resistant. Metabolism: Clinical and Experimental $1995 \mathbf{4 4} 1126-1129$.

29 Alford FP, Hew FL, Christopher MC \& Rantzau C. Insulin sensitivity in growth hormone (GH)-deficient adults and effect of $\mathrm{GH}$ replacement therapy. Journal of Endocrinological Investigation 199922 28-32.

30 Rosenfalck AM, Maghsoudi S, Fisker S, Jorgensen JO, Christiansen JS, Hilsted J et al. The effect of 30 months of low-dose replacement therapy with recombinant human growth hormone (rhGH) on insulin and C-peptide kinetics, insulin secretion, insulin sensitivity, glucose effectiveness, and body composition in GH-deficient adults. Journal of Clinical Endocrinology and Metabolism 200085 4173-4181.

31 Bulow B \& Erfurth EM. A low individualized GH dose in young patients with childhood onset GH deficiency normalized serum IGF-I without significant deterioration in glucose tolerance. Clinical Endocrinology $1999 \mathbf{5 0} 45-55$.

32 Merimee TJ, Hollander W \& Fineberg SE. Studies of hyperlipidemia in the HGH-deficient state. Metabolism: Clinical and Experimental 197221 1053-1061.

33 Rosen T, Eden S, Larson G, Wilhelmsen L \& Bengtsson BA. Cardiovascular risk factors in adult patients with growth hormone deficiency. Acta Endocrinologica 1993129 195-200.

34 de Boer H, Blok GJ, Voerman HJ, Phillips M \& Schouten JA. Serum lipid levels in growth hormone-deficient men. Metabolism: Clinical and Experimental $1994 \mathbf{4 3} 199-203$.

35 Myant NB. The Biology of Cholesterol and Related Steroids, pp 578-580. London, UK: William Heinemann Medical Books Ltd, 1981.

36 Binnerts A, Deurenberg P, Swart GR, Wilson JH \& Lamberts SW. Body composition in growth hormone-deficient adults. American Journal of Clinical Nutrition 199255 918-923.

37 Reaven GM. Banting lecture 1988. Role of insulin resistance in human disease. Diabetes 198837 1595-1607.

38 Eden S, Wiklund O, Oscarsson J, Rosen T \& Bengtsson BA. Growth hormone treatment of growth hormone-deficient adults results in a marked increase in Lp(a) and HDL cholesterol concentrations. Arteriosclerosis and Thrombosis 199313 296-301.

39 Garry P, Collins P \& Devlin JG. An open 36-month study of lipid changes with growth hormone in adults: lipid changes following replacement of growth hormone in adult acquired growth hormone deficiency. European Journal of Endocrinology $1996 \mathbf{1 3 4}$ $61-66$.

Received 13 December 2001

Accepted 26 March 2002 